\title{
Bibliometric observation of publication output of university teachers: A study with special reference to physics
}

\author{
S. Aswathy*, A. Gopikuttan ${ }^{1}$ \\ Sr. Sci. Asst, Library and Documentation Division, Liquid Propulsion Systems Centre, Indian Space Research Organisation, \\ Thiruvananthapuram, ${ }^{1}$ Associate Professor, Department of Library and Information Science, University of Kerala, Kerala, India
}

\begin{abstract}
Context: Bibliometrics are now considered as an established practice to assess the academic output of research. Publication productivity is expressed by the number of papers published by a selected unit in a given time. In Kerala, although higher education and research have much wider importance and the publication productivity is also increasing, no systematic attempt has been made to analyze the pattern of this literature productivity. In this context, it is relevant to examine the productivity patterns of the faculty members of the universities. Materials and Methods: This study is based on the data collected from the publications of teachers pertaining to physics department of the three universities of Kerala that is, University of Kerala, Mahatma Gandhi University and University of Calicut collected from annual reports and the university websites. Analysis is based onbibliometric techniques: To find out authorship pattern, degree of collaboration (DC), fitness of Lotka's law, year-wise and designation-wise distributions. Results: It is found that the DC among the teachers is high among the physics faculties of Universities. Lotka's law seems to be satisfactory in UoC only. Nonopen access journals are preferred by the physics teachers, but seem a slight shift in the use of open access journals is also there. Designation-wise distribution shows that professors are the major contributors to the physics literature. Conclusion: It can be concluded that universities can attain visibility, prestige, and credibility in the broader academic community by producing high-quality research and this in turn enhance the reputation of the universities and provide a greater opportunity for attracting better students and faculty.
\end{abstract}

Keywords: Authorship Pattern, bibliometrics, degree of collaboration, Lotka's law, relative growth rate and doubling time

\section{INTRODUCTION}

Publication productivity is often considered to measure the prestige of an institution and is associated strongly with an individual faculty member's reputation, visibility, and advancement in the academic reward structure, particularly at research institutions and universities (Creamer, 1990). ${ }^{[1]}$ The relationship between output of research and input

*Address for correspondence:

E-mail: aswathysf@gmail.com

\begin{tabular}{|l|l|}
\hline \multicolumn{2}{|c|}{ Access this article online } \\
\hline Quick Response Code: & Website: \\
\hline & www.jscires.org \\
& Dol: \\
& $10.4103 / 2320-0057.156017$ \\
\hline
\end{tabular}

measured through the publication productivity. The contribution of the institution and the individual scientists engaged in research are highlighted by the institutional productivity. It also provides some insights into the complex dynamics of research activity and enables policy makers and administrators to provide adequate facilities and gauge the research activities in a proper direction. A well-known research productivity indicator is the number of publications produced by scientists, institutions, or research groups. To evaluate the productivity of research institutions and individual researcher and to map the growth of the research area scientometric and bibliometric techniques have become tools over the years.

Bibliometrics are now used in quantitative research assessment exercises of academic output. This enhances the reputation of the universities which, in turn, provides a greater opportunity for attracting better students 
and faculty (Clark, 2009). ${ }^{[2]}$ One of the ways in which academic institutions determine the research productivity of faculty members is by looking at the quality of journals in which they publish. The present study analyzes the publication pattern of faculty members of physics departments of the three selected general universities of Kerala: University of Kerala (UoK), Mahatma Gandhi University (MGU) and University of Calicut (UoC). Efforts have also been made to study the time interval in publishing one article by faculty members and the variations in publications.

Universities have a vital role in the generation of new ideas/information, developing, improvising, and accumulating the processed information and transmitting knowledge to the society. Higher education has long been recognized as a major contributing factor to the social, cultural and intellectual life of society by improving the quality of human life Kerala is the most literate state in India. Even though there are three central, 11 states and two deemed universities and among the 11 state universities in Kerala, four are multi-disciplinary in nature. Present study confines to the analysis of the productivity of teachers of the science departments of three universities: UoK, MGU, and UoC which are the old universities established years ago as well as catering to multi-disciplinary subjects. Even though universities produce numerous publications, only a few attempts have been made to analyze these publications previously. Sudhier (2010) ${ }^{[3]}$ carried out a study based on the journals cited by the physicists at UoK to examine the applicability of Bradford's law of scattering on a sample of 303 journals containing 2655 citations collected from 12 doctoral theses during the period 2004-2008. Bandyopadhyay (2011) $)^{[4]}$ mentions the result of the study of references appended to 92 doctoral theses submitted to the departments of mathematics, physics, mechanical engineering, philosophy and political science, Burdwan University, India, from 1981 to 1990. Authorship pattern including multiple authorship, degree of collaboration (DC), and their change with time was also studied. A study carried out by Aswathy and Gopikuttan (2013) ${ }^{[5]}$ analyses the publication pattern of faculty members of three universities in Kerala viz., UoK, MGU and UoC including Authorship pattern, DC, the appropriateness of Lotka's inverse square law and year-wise and designation-wise distributions and found that multi-authorship dominates among university teachers and there is no statistically significant difference between the experience and productivity.

\section{Objectives}

Following objectives have been formulated for analysis:

- To find out the year-wise distribution

- To analyze the authorship pattern and DC

- To analyze the relative growth rate (RGR) and doubling time (DT)

- To categorize open access $(\mathrm{OA})$ and nonopen access journals

- To examine the fitness of Lotkas inverse square law

- To verify the designation-wise categorization of contributions.

\section{METHODOLOGY AND LIMITATIONS}

The study confined to a period of 5 years from 2005 to 2009 of the three general universities in Kerala. A survey has been conducted to collect data from the faculty members of Physics Departments and annual reports, as well as the websites. The analysis includes nine faculty members and 71 publications from UoK, eight faculty members and 60 articles from MGU, and 11 faculties and 86 articles from UoC. The journal publications including national and international journals are considered for the present study. But no effort has been made to analyze the coverage of these journals in international databases such as Scopus and Web of Science. Analysis is done using excel for tabulation and calculation.

\section{Year-wise Distribution}

The total productivity of university faculties is tabulated and consolidated in Table 1 for the period of 2005-2009. It is found that physics department of UoK has a total of 71 articles, MGU and UoC have 60 and 86 articles, respectively. The year 2007 is most productive for all the three universities with 23, 24, and 27 articles, respectively. The minimum number of papers produced from UoK is in the year 2009. MGU had the minimum number of paper in the year 2005 with four papers and as far as UoC is concerned, minimum number of paper were 11 in the year 2005. There is no steady increase in the number of publications; instead, there are ups and downs in the number of publications. The study of Gopikuttan and Aswathy (2014) ${ }^{[6]}$ found that in UoK even though there is an increase in the publication output, but it is not a linear growth.

The data [Table 1] indicate a percentage-wise representation of the publication output. The percentage wise distribution shows 
that the maximum number of papers was from UoC $(39.63 \%)$, and minimum number of papers was from MGU (27.65\%). UoK has $71(32.72 \%)$ article during the period [Table 2].

\section{Authorship pattern}

As per the data obtained [Table 3] during the study period, a total number of 217 papers had produced by the teachers from the physics departments of the concerned universities. In UoK, multi-authored papers are high compared to single-authored papers, which is only one. In MGU, eight papers were single authored, 13 two authored and 9 three authored papers. UoC has 22 single authored papers, 23 two authored and 10 three authored papers. In all the universities, multi-authored papers are more in number. These results of multi-authorship reveal the team-centric research in universities.

\section{Degree of collaboration}

The data show that the extend of collaboration is measured according to the existing number of multi-authored papers. To measure the collaborative research pattern, a simple indicator called collaboration coefficient is used. Collaboration co-efficient is the ratio of the number of collaborative

Table 1: Year-wise distribution

\begin{tabular}{lccc}
\hline Year & UoK & MGU & UoC \\
\hline 2005 & 13 & 4 & 11 \\
2006 & 12 & 11 & 17 \\
2007 & 23 & 24 & 27 \\
2008 & 17 & 10 & 15 \\
2009 & 6 & 11 & 16 \\
Total & 71 & 60 & 86 \\
\hline
\end{tabular}

UoK= University of Kerala, MGU = Mahatma Gandhi University, $\mathrm{U} O \mathrm{C}=$ University of Calicut

Table 2: Year-wise growth

\begin{tabular}{lcc}
\hline University & No. of publications & Percentage \\
\hline UoK & 71 & 32.72 \\
MGU & 60 & 27.65 \\
UoC & 86 & 39.63 \\
Total & 217 & 100 \\
\hline
\end{tabular}

UoK = University of Kerala, MGU = Mahatma Gandhi University, UoC $=$ University of Calicut research papers during a certain period of time. The formula given by Subramanyam (1983 $)^{[]]}$is used to determine the DC in quantitative terms. According to him, the visibility and productivity of scientists are affected by the collaboration. He identified six types of author collaboration such as teacher-pupil collaboration, collaboration among colleagues, supervisor-assistant collaboration, researcher-consultant collaboration, collaboration between organizations and international collaboration.

The states that:

$$
\mathrm{C}=\frac{\mathrm{NM}}{\mathrm{NM}+\mathrm{NS}}
$$

where,

$\mathrm{C}=$ Degree of collaboration,

$\mathrm{NM}=$ Number of multi-authored papers and

NS $=$ Number of single-authored papers.

In the present study DC for the three universities are the following:

University of Kerala: NM $=70$ and $\mathrm{NS}=1$, thus $C=\frac{7}{70+1}$ that is, 0.98 Thus the DC 0.98 which clearly indicates its dominance upon multi-authored contribution.

Mahatma Gandhi University: NM $=52$ and NS $=8$, thus $C=\frac{52}{52+8}$ that is, 0.86 Thus the DC 0.86 which clearly indicates its dominance upon multi-authored contribution.

University of Calicut: NM $=64$ and NS $=22$, thus $C=\frac{64}{64+22}$ that is, 0.74 Thus the DC 0.74 indicates its dominance upon multi-authored contribution.

Since all the results are tending toward 1, the average DC is 0.86 it is understood that DC is high in among physicists in universities.

Table 3: Authorship pattern

\begin{tabular}{|c|c|c|c|c|c|c|c|c|}
\hline \multicolumn{3}{|c|}{ UoK } & \multicolumn{3}{|c|}{ MGU } & \multicolumn{3}{|c|}{ UoC } \\
\hline No of authors & No of papers & $\%$ & No of authors & No of papers & $\%$ & No of authors & No of papers & $\%$ \\
\hline Single & 1 & 1.40 & Single & 8 & 13.33 & Single & 22 & 25.58 \\
\hline Two & 18 & 25.35 & Two & 13 & 21.66 & Two & 23 & 26.74 \\
\hline Three & 20 & 28.16 & Three & 9 & 15 & Three & 10 & 11.62 \\
\hline More than three & 32 & 45.07 & More than three & 30 & 50 & More than three & 31 & 36.04 \\
\hline Total & 71 & 100 & & 60 & 100 & & 86 & 100 \\
\hline
\end{tabular}

UoK= University of Kerala, MGU $=$ Mahatma Gandhi University, UoC $=$ University of Calicut 


\section{Collaborative Index}

Collaborative index $(\mathrm{CI})$ is the mean number of authors per joint authored publications. The mathematical representation of $\mathrm{CI}$ is as follows.

$\mathrm{CI}=\frac{\text { Number of authors of total joint publications }}{\text { Total joint publications }}$

It is found that CI for UoK is 0.089 , which is high compared to MGU and $\mathrm{UoC}$ which is 0.177 and 0.169 , respectively [Table 4].

\section{Relative Growth Rate and Doubling Time}

Relative Growth Rate is a measure to study the increase in number of articles/pages per unit of articles/pages per unit of time. It has derived originally from the study of the rate and of interest in the financial investment (Blackman, 1919) ${ }^{[8]}$ and from the study of growth analysis of individual plants effectively applied in the field of Botany (Hunt, 1978). ${ }^{[9]}$ Mean RGR of articles over a specific period of interval is calculated mathematically as

$R(P)=\frac{\log _{e} 2 P-\log _{e} 1 P}{2^{\mathrm{T}}-1^{\mathrm{T}}}$

Here $\mathrm{R}(\mathrm{P})=\mathrm{RGR}$ of articles over the specific period of time.

$\log _{e} 1 P=\log$ of initial number of articles.

$\log _{\mathrm{e}} 2 \mathrm{P}=\log$ of final number of articles.

$2^{\mathrm{T}-} 1^{\mathrm{T}}=$ Unit difference between the initial time and the final time.

Doubling time is directly related to RGR. It is the time required for articles to become double of the existing amount. Further, if the number of articles in a subject doubles during a given period, then the difference between the number at the beginning and at the end of this period must be the logarithm of the number 2. If the natural logarithm is used, this difference has a value of 0.693 .

Thus, the corresponding DT is calculated mathematically as;

$\mathrm{DT}=\frac{\log _{\mathrm{e}} 2}{\mathrm{R}}=\frac{0.693}{\mathrm{R}} \mathrm{R}=\mathrm{RGR}$

Table 5 shows the RGR of the three universities. The mean RGR of UoK is 0.43 , and MGU and UoC are 0.678 and 0.51 , respectively. The mean DT for the three universities is $3.03,1.925$, and 2.0325 , respectively. In all the universities under investigation, the results indicate toward the slow growth rate of publications.

\section{Open Access and Subscription based Journals}

An attempt has been made to categorize the journals as $\mathrm{OA}$ and Subscription based journals, which is provided in tabular form [Table 6]. In UoK, 6 article contribution was in $\mathrm{OA}$ journals while in MGU the contributions in OA journals are less that is, two articles. In UoC, article contribution in $\mathrm{OA}$ journals is maximum that is, 10 .

Table 4: Collaboration index

\begin{tabular}{lc}
\hline University & Collaborative index \\
\hline University of Kerala & 0.089 \\
Mahatma Gandhi University & 0.177 \\
University of Calicut & 0.169 \\
\hline
\end{tabular}

Table 5: Relative growth rate and doubling time

\begin{tabular}{rcccccc}
\hline Year & $\begin{array}{c}\text { No. of } \\
\text { articles }\end{array}$ & $\begin{array}{c}\text { Cum. no. } \\
\text { of articles }\end{array}$ & $\begin{array}{c}\text { Loge } \\
\text { 1P }\end{array}$ & $\begin{array}{c}\text { Loge } \\
\text { 2P }\end{array}$ & $\begin{array}{c}\text { RGR or } \\
\text { R (P) }\end{array}$ & $\begin{array}{c}\text { Doubling } \\
\text { time (DT) }\end{array}$ \\
\hline UoK & & & & & & \\
2005 & 13 & 13 & & 2.56 & & \\
2006 & 12 & 25 & 2.56 & 3.22 & 0.66 & 1.05 \\
2007 & 23 & 48 & 3.22 & 3.87 & 0.65 & 1.07 \\
2008 & 17 & 65 & 3.87 & 4.17 & 0.3 & 2.31 \\
2009 & 6 & 71 & 4.17 & 4.26 & 0.09 & 7.7 \\
& & & & & $\begin{array}{c}\text { Mean } \\
\text { R=0.43 }\end{array}$ & $\begin{array}{c}\text { Mean } \\
\text { DT }=3.03\end{array}$ \\
& & & & & &
\end{tabular}

MGU

\begin{tabular}{ccccccc}
2005 & 4 & 4 & & 1.39 & & \\
2006 & 11 & 15 & 1.39 & 2.71 & 1.32 & 1.05 \\
2007 & 24 & 39 & 2.71 & 3.67 & 0.96 & 1.07 \\
2008 & 10 & 49 & 3.67 & 3.89 & 0.22 & 2.31 \\
2009 & 11 & 60 & 3.89 & 4.1 & 0.21 & 7.7 \\
& & & & & $\begin{array}{c}\text { Mean } \\
\text { Rean }\end{array}$ & $\begin{array}{c}\text { Mean } \\
\text { DT=1.925 }\end{array}$ \\
UoC & & & & & & \\
2005 & 11 & 11 & & 2.4 & & \\
2006 & 17 & 28 & 2.4 & 3.33 & 0.93 & 0.75 \\
2007 & 27 & 55 & 3.33 & 4.01 & 0.68 & 1.02 \\
2008 & 15 & 70 & 4.01 & 4.25 & 0.24 & 2.89 \\
2009 & 16 & 86 & 4.25 & 4.45 & 0.2 & 3.47 \\
& & & & & Mean & Mean \\
& & & & & R=0.51 & DT=2.0325 \\
\hline
\end{tabular}

$\mathrm{DT}=$ Doubling time, $\mathrm{RGR}=$ Relative growth rate, UoK=University of Kerala, $M G U=$ Mahatma Gandhi University, $U o C=$ University of Calicut

Table 6: OA vs. non OA Journals

\begin{tabular}{lcc}
\hline Name of University & OA Journals & Non OA Journals \\
\hline University of Kerala & 6 & 28 \\
Mahatma Gandhi University & 2 & 36 \\
University of Calicut & 10 & 26 \\
\hline
\end{tabular}




\section{Fitness of Lotka's inverse square law}

Lotka's law (1926) ${ }^{[10]}$ has been applied to count the author productivity. According to this law, the number of scientist who contributed " $n$ " papers must be $\frac{1}{n^{2}}$ of those who contribute only one paper. The simplest equation to represent Lotka's law is as follows:

$X^{n} Y=C$

where, $\mathrm{X}$ is the number of contributions,

$\mathrm{Y}$ is the number of authors and $\mathrm{C}$ is a constant. That is,

$Y=\frac{C}{X^{n}}$ or $X^{n} Y=C$

For the first dataset, from $1^{\text {st }}$ row,

$X^{n} Y=C$ that is, $1^{n} X 2=2$

Therefore, $\mathrm{C}=2$.

From $2^{\text {nd }}$ row,

$2^{n} \times 2=2$ and $2^{n}=1$ (takinglogon both side)

$\mathrm{n} \log 2=\log 1$, since $\log 1=0$, so $\mathrm{n}=0$. (Note: $\left.2^{0}=6^{0} \ldots=1\right)$

For the $2^{\text {nd }}$ data set, $1^{\mathrm{n}} \mathrm{X} 1=\mathrm{C}$ that is, $\mathrm{C}=1$.

From the second row,

$2^{n} \times 1=1,2^{n}=1$

$\mathrm{n} \log 2=\log 1$ and $\mathrm{n}=0$. (Note: $1^{0}=2^{0}=3^{0} \ldots=1$ ).

For the third data set, from the $1^{\text {st }}$ row,

$1^{n} \times 8=C$, then $\mathrm{C}=8$.

From the $2^{\text {nd }}$ row, $2^{n} \times 3=8,2^{n}=\frac{8}{3}=2.6667$,

$n \log 2=\log 2.6667$

Therefore, $n \times 0.3010=0.4259$ and $\mathrm{n}=1.42$

Thus, the exponent of " $\mathrm{n}$ " is found 0 for first two data sets and 1.42 for the third data set. Here for the UoK and MGU, Lotka's inverse square law is found unfit. The law is fit for the data set of UoC. The table shows the number of observed and expected authors which indicates the unfitness of the law to UoK and MGU [Table 7].

\section{Designation-wise Distribution}

The designation-wise distribution of the publication output of all the three universities is provided here [Table 8]. Designation-wise analysis of UoK clearly shows that the professors are having high contributions at their credit followed by Reader and Associate Professor. In MGU also, professors have 50 papers at their credit while Associate Professors have only 10 papers at their credit. In UoC, 52 papers were contributed by Professors while Associate Professors contributed 31 papers. Only three papers were contributed by Readers.

\section{Major findings}

Multi-authored papers are more than single-authored publications in all the three universities. Collaborative Index for all the three universities is 0.089, 0.177, and 0.169 , respectively. There is a steady but slow rate of growth in the article contributions. In the case of article contributions, 2007 is most productive year for all the three universities. The percentage wise distribution shows that maximum number of papers was from UoC (39.63\%), and minimum number of papers was from MGU (27.65\%). UoK has $35.72 \%$ of article contribution. Lotka's inverse square law found to be unfit for UoK and MGU while

Table 7: Lotka's inverse square law

\begin{tabular}{|c|c|c|c|c|c|c|c|c|}
\hline \multicolumn{3}{|c|}{ UoK } & \multicolumn{3}{|c|}{ MGU } & \multicolumn{3}{|c|}{ UoC } \\
\hline $\begin{array}{l}\text { No, of } \\
\text { articles (X) }\end{array}$ & $\begin{array}{l}\text { No of authors } \\
\text { observed (Y) }\end{array}$ & $\begin{array}{l}\text { No. of authors } \\
\text { expected with } \\
\text { Y with } n=0\end{array}$ & $\begin{array}{c}\text { No, of } \\
\text { articles (X) }\end{array}$ & $\begin{array}{l}\text { No of authors } \\
\text { observed (Y) }\end{array}$ & $\begin{array}{l}\text { No. of authors } \\
\text { expected with } \\
\text { Y with } n=0\end{array}$ & $\begin{array}{c}\text { No, of } \\
\text { articles (X) }\end{array}$ & $\begin{array}{l}\text { No of authors } \\
\text { observed }(Y)\end{array}$ & $\begin{array}{l}\text { No. of authors } \\
\text { expected with } \\
\text { Y with } n=1.42\end{array}$ \\
\hline 1 & 2 & 2 & 1 & 1 & 1 & 1 & 8 & 1 \\
\hline 2 & 2 & 2 & 2 & 1 & 1 & 2 & 3 & 1 \\
\hline 6 & 1 & 2 & 4 & 2 & 1 & 4 & 3 & 1 \\
\hline 8 & 1 & 2 & 5 & 3 & 1 & 10 & 1 & 1 \\
\hline 17 & 1 & 2 & 12 & 1 & 1 & 13 & 1 & 1 \\
\hline 34 & 1 & 2 & 22 & 1 & 1 & 24 & 1 & 1 \\
\hline
\end{tabular}

UoK= University of Kerala, MGU = Mahatma Gandhi University, UoC = University of Calicut 
Table 8: Designation-wise distribution of articles

\begin{tabular}{lcc}
\hline Name of University & OA Journals & Non OA Journals \\
\hline University of Kerala & 6 & 28 \\
Mahatma Gandhi University & 2 & 36 \\
University of Calicut & 10 & 26 \\
\hline
\end{tabular}

for UoC the law fits exactly. The total number of journals in which the faculty members of the three universities publish their articles are 34, 38, and 36, respectively. In all the three universities, the RGR decreased, and the corresponding DT has increased which shows the slow growth rate. OA journals are less preferred compared to Non OA journals, and the designation-wise analysis shows that professors are having more publications than other teachers.

\section{CONCLUSION}

It is found that at the early stage, the publication productivity of from these universities was less but it is increasing gradually, even though there are ups and drop downs. DC is high which indicates the high collaborative and team research in these universities. In UoK and MGU, the Lotka's law is unfit but in UoC, the law seems to be satisfied. The team research of the faculty and students of universities result in joint authorship which results in high collaboration. The study reveals that team research is predominant among university teachers. Bibliometric studies help to evaluate the quality and quantity of research output and the visibility of these publication outputs which in turn throw light the strength and weakness in infrastructure and other problems. It can be concluded that Universities can attain visibility, prestige, and credibility in the broader academic community by producing high-quality research and this in turn enhances the reputation of the universities and provides a greater opportunity for attracting better students and faculty.

\section{REFERENCES}

1. Creamer EG. Assessing Faculry Publication Productivity: Issues of Equity. Eric Digest; 1990. p. 1-6.

2. Clark JG, Warren J, Yoris A. Assessing researcher publication productivity in the leading information systems journals: A 2003-2007 update. Commun Assoc Inf Sys 2009;24:225-54.

3. Sudhier KG. Bradford's law of scattering revisited: A study based on the references in doctral theses in the area of physics. Collnet J Scientometrics Inf Manage 2010;4:1-13.

4. Bandyopadhyay AK. Authorship pattern in different disciplines. Ann Libr Inf Stud 2011;48:139-47.

5. Aswathy S, Gopikuttan A. Productivity pattern of universities in Kerala: A scientometric analysis. Ann Libr Inf Stud 2013;60:176-85.

6. Gopikuttan A, Aswathy S. Publication productivity of University of Kerala: A sicnetometric analysis. DESIDOC J Libr Inf Technol 2014;34:131-9.

7. Subramanyam K. Bibliometric studies of research collaboration: A review. J Inf Sci 1983;6:33-8.

8. Blackman HV. Compound interest law and plant growth. Ann Bot 1919;33:353-60.

9. Hunt R. Plant Growth Analysis. USA: Edward Arnold; 1978.

10. Lotka AJ. Frequency distribution of scientific productivity. Journal of the Washington Academy of Science 1926;16:317-23.

How to cite this article: Aswathy S, Gopikuttan A. Bibliometric observation of publication output of university teachers: A study with special reference to physics. J Sci Res 2015;4:14-9.

Source of Support: Nil, Conflict of Interest: None declared 